\section{ON A CASE OF SPASMODIC SYRINGOMYELIA.}

By JUDSON S. BURY, M.D.LoNd., F.R.C.P., PHYSICIAN TO THE MANCHESTER ROYAL INFIRMARY.

There are few diseases in which the symptoms present so many variations, both in kind and in grouping, as in syringomyelia. The most characteristic features of the disease are: Loss of sensibility to pain and temperature affecting portions of the arms and the upper part of the chest; muscular atrophy resembling in its distribution and progress that of "progressive muscular atrophy," and trophic disturbances of the skin, bones, and joints. Associated with these symptoms there may be loss of tactile sensibility, a spastic weakness of the legs varying much in intensity, ataxia, enlargement of a limb, or signs of implication of some of the cranial nerves, or of the cervical sympathetic. According to the presence or absence of any of these symptoms, to their relative preponder. ance and to the variations in their combination, the diagnosis in certain cases may be difficult, and may involve a consideration of disseminate sclerosis, disseminated forms of myelitis, cervical pachy. meningitis, amyotrophic lateral sclerosis, ataxia paraplegia, and bulbar paralysis.

With regard to spasm, this as a rule is but little marked in syringomyelia, muscular hypertonus being often only expressed by exaggeration of the kneejerk. Sometimes it is more in evidence, and in the legs may be associated with definite paralysis ; then, if the muscles of the arms are atrophied, the case, apart from sensory phenomena, may closely resemble one of amyo. trophic lateral sclerosis. Very rarely muscular spasm is so marked and so widespread that it constitutes the dominant feature of the case. This spasmodic form of syringomyelia was first described by P. Marie in 1900. Two years later one of his pupils, G. Guillain, wrote a thesis on the subject, in which, after a careful analysis of five cases, he enumerated the follow. ing symptoms as characteristic of the fully developed condition :

1. The arms are firmly applied to the sides of the chest, the elbows are slightly flexed, the wrists are extended, and the hands tend to meet in front of the pubis. The shoulders are raised and projected forwards, and a hollow is formed by the sinking in of the upper part of the sternum and the adjacent cartilages; the bead is also inclined forwards, and is sunk between the shoulders. The back is rounded; the external border of the trapezius is often unduly prominent. The attitude is a rigid one, and resembles that of paralysis agitans.

2. The position of the hand is peculiar; besides being hyperextended, like the hand of a preacher, the three inner fingers are firmly flexed into the palm, and tend to recoil like a spring after they have been forcibly extended, but the thumb and index finger remain extended, und for a long time preserve a certain degree of movement which is like that of a pincers.
3. Limitation of movement, which affects all four limbs and sometimes the head, is mainly due to muscular rigidity.

4. The knee-jerks are greatly exaggerated, ankle-clonus is easily elicited, and the plantar reflex gives an extensa: response.

5. The evolution of the malady is very slow, and ite duration long, lasting often for more than twenty years. Death is frequently the result of septic infection from a paralysed, and often an ulcerated, bladder.

Guillain made a pathological examination in two cases. He found intense degeneration of the pyramidal tracts in their whole length in the cord; to this degeneration, more marked than that usually found in syringomyelia, he attributes the spasmodic condition. Since his thesis Guillain, in conjunction with Alquier and Raymond, has de. scribed two more cases. Other cases have been reported by Raymond and Français, Verger and A. Bruce. In Bruce's case, which he diagnoses as probably a very early instance of the spasmodic form of syringomyelia, the symptoms were limited to the left arm; this showed the characteristic attitude, and there w a s dissociated sensibility of portions of the hand and forearm. In addition to muscular spasm, the skin and sub. cutaneous tissues of the arm were much thickened and the muscles were un. duly firm; the condition was one of scleroderma. and fibromyositis.

The following case, which was recently under my care at the Manchester Koyal Infirmary, corresponds in its main features with the description given by Guillain of the spasmodic variety of syringom myelia.

Case.

M. W., aged 30, was bors in Yorkshire, and has always lived in England. Between the ages of 5 and 7 he had "fainting fits," about one attack a week, in which he attack a week, in which he lost consciousness ; there was no struggling, no biting of the tongue, nor involunabout 21 years of age he contracted gonorrhoes, but. contracted gonorrhoea, but. denies having had syphilis.
In 1893 (aged 20) he was. medically examined for the railway service, and was passed as quite bealthy. In 1897 (aged 24) curvature of the spine was noticed. In 1900 (aged 27) his left arm became weak, and gradually got weaker and stiffer. In 1903 (aged 30) the left leg. began to get weak, and a few months later the right arm and the right leg. During the year $1904 \mathrm{his}$ legs got steadily weaker and stiffer; his left leg used to jerk spasmodically at times, and the right leg became very tremulous under the influence of emotion or exertion. In January, 1905 (aged 32) he was obliged to give up work, and he entered University College Hospital under Sir Thomas Barlow. Six weeks later he went into the National Hospital under Dr. Risien Russell. at the Manchester Royal Infirmary, when the following notes. were taken: Patient is a short, thin man, very poorly nourished, unable to stand without support. There is a marked lateral curvature of the dorsal spine, with the convexity to the left: the left side of the thorax bulges posteriorly. The shoulders are raised and project forwards; the upper part of the chest presents a distinct hollow. These features are well shown in the accompanying figures, from photographs.

The patient is unable to sit up in bed, his trunk is very rigid. The patient is unle to sit up in bed, his trank is vory jig. left arm is anch pressed against the side of the chest, the elbow is slightly 
flexed, the wrist is hyper-extended. The whole limb is very rigid, and much force is required to bend its joints. All the finger-joints are flexed, the index finger being less bent than the other fingers; the distal joint of the thumb is hyperextended, and is usually pressed against the first finger. The right arm is also rigid, but patient can feebly move can feebly move it at shoulder, elbow, wrist, and is strongly prois strongly proonly slight power only slight power to supinate it. The fingers are the metacarpophalangeal joints, and slightly flexed at the phalangeal joints; the index finger is less rigid than the other fingers. Patientcan feebly lift his legs from the bed, and can bend and extend the knees; ankles, and toes; all these movements are very difficult owing to muscular rigidity. abduction of the thighs are stronger than other move. ments. The cight leg is cight leg is left left one, on movemont it shows a fine rapid tremor. The left leg is occasionally drawn up by spasm. The dimbs are very thin, but there is no obvious muscular atrophy. elbow, and knee jerks are exaggerated; there is marked ankle clonus; the plantar reflex is extensor in type; the superficial abdominal reflexes are present. The patient is free from pain, and from other abnormal subjective sensa-

tions. The sation as tested by squeezing the muscles is normal. Tactile sensibility is not impaired except to a slight degree on the hands and feet. Sensibility to pain is abolished or considerably diminished all over the body, with the exception of the exception of portions of the bility. bility to heat and cold is slso diminished, but patient's answers are so variable thet it is difficult to define the limits of the loss. The mental condition is normal. The only signs that any of the cranial nerves are involved are: (1) Marked ars: patient looks towards the left

side; and (2) analgesia of the face. The bladder and rectum are not affected. The patient was treated with massage, and his spine was exposed to the Roentgen rays thrice weekly. This treatment was followed by an improvement in the flexibility
of the limbs and in the movements of the right arm.
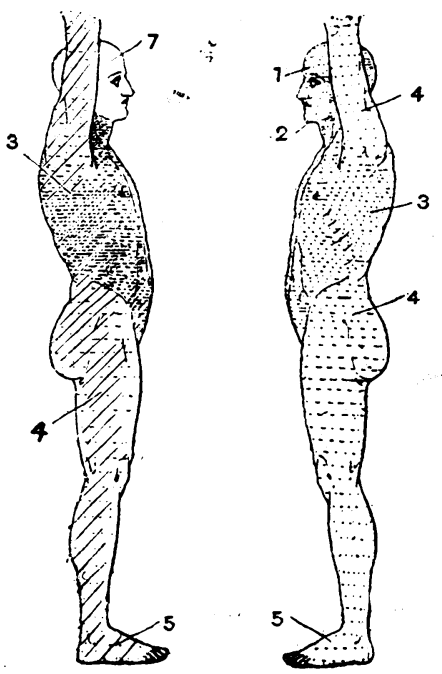

He left the hospital on August 21st, was readmitted on September 25th, 1907, and was discharged on December 11th. At this time his condition was much the same as formerly. The following minor differences were observed: The limbs and body were more rigid, there was no voluntary power to move the left arm at the superficial abdominal reflexes were absent were absent. On October $22 \mathrm{nd}$, slight improvepower of the right arm was noted; arm was noted; buted to daily massage. Patient was admitted to hospital for a third time last July, and re mained under treatment until November. thought that daily massage did him good and lessened the tendency to tremor In other respects no m a terial change in his condition was observed. Tactile sensibility was normal with the exception of a small area over the trunk. Sensibility to pain and temperain and temperature was most diminocciput, the neck, and the trunk; it was less limbs, and was nearly normal over the left arm. On both arms a cold test - tube was occasionally thought to be warm. On the legs the temperature sense was only definitely diminished over the left thigh. Slight variations in the distribution and the condition of sensation were noted on different occasions; the accompanying charts were made shortly before he left the hospital.
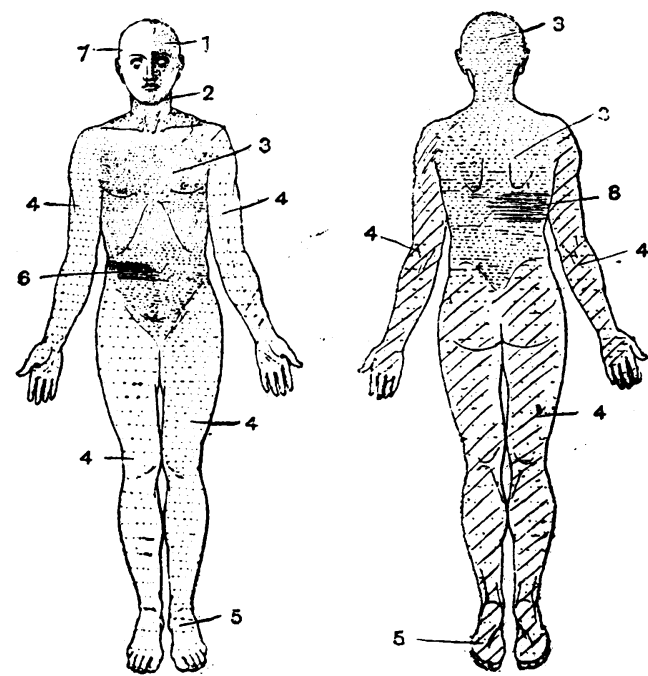

1, Impaired sensation to pain; temperature sense normal. 2, Impaired sensation to tem perature only. 3, In sensation to both pain and tectiol 7, Sensation normal. 8, Slightly impaired tactile atrophy in the arms. In all probability the cavity occupies a considerable length of the spinal cord, and there is evidence in the presence of nystagmus and of analgesia of the face that the lesion extends into the bulbar region.
In its main featuresintense and widespread rigidity, the peculiar attitude of the upper part of the dissociated sensibility-this sponds to the spasmodic form of syringomyelia, and it admit the possi. bility of any other diagnosis. might be caused by cervical pachymenigitis, but in this con. dition we should expect pain , and there is case corre. The rigidity 
The extreme muscular rigidity suggests that the pyramidal tracts are severely implicated.

Bibliography.

G. Guillain; La forme spasmodiqu. de la suringomyélie. Paris, 1902. Alquier et Guillain : Etude anatome-clinique d'un cas de syringomyélie. Rev. Neurol., 1906, n. 489 .

Raymond et Guillain : Un cas de syringobulbie. Syndrome d'Avellis au cours d'une syringomyelie spasmodique. Rev. Neurol., 190s, p. 41. particulière des membres supérieurs. Rev. Neurol., 1906, p. 350 .

H. Verger: Sur un cas de syringomyélie spasmodique douloureuse à A. Bruce: A Case of Sphate, 1907, p. 21.

Review of Neurology and Psychiatry, 1908, p. 390.

\section{DRY IODINE CATGUT.}

WILLIAM S. DICKIE, F.R.C.S.,

SURGEON, NORTH RIDING INFIRMARY. MIDDLESBROEGH.

In the British Medicat Journal of October 2nd, 1909, there appeared a very interesting article by $\mathbf{M r}$. Steward on formalin.iodine catgut. As the subject of absorbable ligature and suture material is of constant interest, an account of my experiences with catgut sterilized by means of iodine may not be out of place.

I have used iodine catgut in one form or another for more than four years. At first I used ordinary raw catgut prepared by Claudius's method and preserved in the iodine solution. The great disadvantage attending its use is the brittleness which speedily develops when the gut lies in the iodine solution for more than ten or fourteen days. Another point to which Mr. Steward refers, namely, the rough and uneven surface which the material sometimes assumes after immersion in the iodine solution, annoyed me occasionally, and it was usually noticeable that the hanks which presented this peculiarity also failed to assume the usual deep brown, almost black colour. The last mentioned defects are not, I think, due to the method of preparation, but to variations in the material itself, because it would sometimes be observed that one or two hanks in a batch were rough and light-coloured, while the others were smooth and dark. However, the defect was more apparent than real, as bacteriological investigation showed that the doubtful hanks were sterile, and the material was just as strong and easy to handle as that presenting the usual appearances. On the whole, the method is satisfactory, and I still use it in hospital practice where a batch of catgut is speedily used up and renewed, because it reduces the preparatory handling to the minimum.

In private practice, however, the conditions were somewhat different; a given quantity of catgut lasted a very much longer time, and it was therefore necessary to prepare it in relatively small quantities and more often, or to take the chance of finding that the latter part of the stock had become rotten.

After reading the memoir on dry iodine catgut by Alexis v. Moschowitz, ${ }^{1}$ I tried the method recommended, and have adhered to it ever since. The plan I follow is this :

I prepare four dozen lengths of one size at a time, because the tins which serve for the final storage of that quantity are of a handy size.

I wrap four dozen special glass slides with notches cut at the ends in a piece of gauze, and place them in a glass jar, and sterilize jar and contents in a steam sterilizer. Of course this preliminary sterilization is not essential; indeed, it is almost superfiuous, since if the iodine solution can be trusted to render the catgut aseptic, it can also be trusted to sterilize the slides and the interior of the jar; still it is just as easy to use a sterile jar and sterile slides and to do the work with clean use a sterile jar and sterile slides and to do

One length of catgut is then wound loosely on each slide. A certain amount of slack is essential, as the gut contracts so much in the solution.

The loaded slides are placed in the jar, and an excess of iodine solution poured over them, and the jar, which is fitted with a ground-in glass cover, is stored in a dark place.

On the tenth day the iodine solution is poured off, and, after waiting for a few hours to allow as much of the fluid as possible to drain from the catgut to the bottom of the jar, the slides are transferred to sterile test tubes.

In a copper tin I place four dozen test tubes, each tube plugged in the ordinary bacteriological fashion with cottonwool, with a layer of Gamgee tissue above and below the tubes; the tin and its contents are sterilized in a high-pressure steam sterilizer for half an hour, and then placed in a gas oven to sterilizer for half an hour, and then placed in a

With gloved hres ar transferred from the jar to the tubes, one slide to each tube, and the cotton-wool plugs are immediately replaced after a preliminary singeing in the flame of a spirit lamp. The cover ing layer of Gamgee tissue is placed over the tubes, the lid put on, and the tin put away upside down for a couple of days to allow of any remaining moistare gravitating from the interior of the tabes into the plugs. At the end of that time the catgut is perfectly dry and the plugs are more or less impregnated with iodine.

Preserved in this way the catgat will keep almost indefinitely and retain its tensile strength unimpaired for years; but perfect dryness is essential, otherwise the material is sure to become brittle.

For a time. I tried sealing the tubes-after the contents were apparently dry-over the cotton-wool plugs with paraffin wax, and again I used tubes fitted with serew caps, but I found no advantage therefrom; indeed I think that the catgut keeps best when a certain degreeof ventilation is allowed through the plugs.

At one time I had some doubts as to the certainty of the tube contents remaining sterile, but repeated bacteriological examinations after the lapse of considerable periods have invariably shown that the catgut was perfectly aseptic, so that for a long time I had no further investigations made. I had in my possession, however, an unopened tube of No. 6 formalin-iodine catgut which had been intended for ligaturing pedicles, etc. The gat had been placed in iodine solution on May 7th, 1906, and transferred to the test tube on May 17th, 1906. I have not used catgut of this size for years, for reasons subsequently to be mentioned, and $I$ felt that in any case I should not care to use this particular specimen, as its asepticity and tensile strength might be doubtful three years and five months after preparation. I therefore sent the unopened tube on October 20th, 1909, to the Clinical Research Association for investigation, and received the following report :

October 28th, 1909. After a preliminary washing to get rid of any disinfectant present, the catgut was incubated in sterile media for one week, half the time under anaërobic condition and the other half under ordinary conditions. After this time living organisms from the catgut.

I myself tested what remained of this specimen of catgut with regard to its tensile strength, and found that it was in no way impaired, the average breaking strain of the knotted catgut being $36 \frac{1}{4} \mathrm{lb}$.

When I first adopted the dry method of preservation I used the ordinary formalin catgut supplied by the dealers as my raw material, but ultimately gave it up, for two reasons.

One was that the formalin catgut never stained deeply in the iodine solution; usually after ten days' immersion it was only of a light brown colour. This was perhaps only a very unimportant matter, as bacteriological investi. gation of the light-coloured strands demonstrated their asepticity, a point which was amply confirmed by clinical experience; still the deep colour provides a somewhat rough but visible guarantee that the iodine has penetrated thoroughly into the material.

The other was that it remained too long unabsorbed. In the great majority of cases this constituted no disadvantage, but in several in which operations had been performed on thin patients with but little subcutaneous tissue-particularly hernia and appendix operationswhere the somewhat balky knot formed by knotting the penultimate loop and the terminal end of the continuous suture uniting the edges of the superficial aponeurosis lay immediately under the cutaneous incision, the knot was ultimately extruded through the long.healed scar four and five weeks after the operation. This difficulty might easily have been obviated by using finer sizes of catgat than the Nos. 2 and 4 which I commonly employ, but, for reasons which I shall subsequently state, I preferred to continue to use the heavier material.

This objection of too long persistence in the tissues also applies to formalin catgut and sulpho-chromic catgut treated by the iodine method and stored in the iodine solution. I therefore returned to the use of ordinary raw catgut, and have used it continuously for three years. Prepared and stored in the way I have described it has proved exceedingly satisfactory. Even after nine months it has been found quite as strong as when first prepared; clinically, I have had no reason to doubt its asepticity. Its surface is perfectly smooth, and it has just a sufficient 